\title{
Improved Asset Design for Educational Asynchronous Games @KAR with Visual Concept of Malang City
}

\section{Andy Pramono and Pujiyanto}

State University of Malang, Malang

\section{Abstract}

All humans, including children, need comfort in life. Games are one of the entertainment for children. According to the Indonesian Ministry of Communication and Informatics data, at least $\mathbf{3 0}$ million children and adolescents in Indonesia are internet users, and digital media is currently the main choice of communication channels they use. There is another perception that interactive games can inhibit children's education, which makes children lazy to learn. This condition is the idea of researchers to create learning media that combines "game" and "learning" which is packaged in Edutainment: @KAR (short for character games). This research is through a descriptive procedural research model, which outlines the steps that must be followed to produce a product. The data obtained in this design was taken by data observation, interview and documentation methods. Data observation method consists of visual data, library data and survey target audience. The importance of this research is as a form of maintenance or preservation of design with the styles of the malang city. With the improvement of @KAR educational game design with the nuances of local wisdom in Malang, there will be an introduction, pride and image enhancement to Indonesian culture, especially the malang city. This research can also be a guide for character education or one of the learning materials.

(c) Andy Pramono and

Pujiyanto. This article is

distributed under the terms of the Creative Commons

Attribution License, which permits unrestricted use and redistribution provided that the original author and source are credited.

Selection and Peer-review under the responsibility of the International Seminar on Language, Education, and Culture Conference Committee.

\section{G OPEN ACCESS}

All humans, including children, need comfort in life. Games are one of the entertainments for children. According to the Indonesian Ministry of Communication and Informatics data, at least 30 million children and adolescents in Indonesia are internet users, and digital media is currently the main choice of communication channels they use. There is another perception that interactive games can inhibit children's education, it makes children lazy to learn. This condition gives an idea to researchers to create learning media that combines "game" and "learning" which is packaged in Edutainment: @KAR (short for character games). This research is done through a descriptive procedural research model, which outlines the steps that must be followed to produce a product. The data used in this design was taken by observation, interview and documentation methods. The observation data consists of visual data, library data and data from target audience. The importance of this research is as a form of maintenance or preservation of design with the styles of the Malang city. With the improvement of @KAR educational game design with the nuances of local wisdom in Malang, there will be an introduction, pride and image enhancement to Indonesian culture, especially the Malang city. This research can also be a guide for character education or one of the learning materials. 


\section{Introduction}

Games are developed in various platforms and not just as entertainment media but also have positive aspects in motoric and intellectual progress. Games support the progress and sustainability of various fields, including education. Some studies say that combining digital media assisted learning systems is a finding that requires deep exploration and has a major impact on the revolution of learning. Games have specific learning content and are intended to improve students' ability to understand a particular material (through game play, narration and visualization) can be called an educational game.

Educational games can be categorized as Interactive Learning Multimedia (MPI). Where the game is able to create, store, present, and re-access information in the form of text, graphics, sound, video, or animation. The appearance and taste of an educational game must be fun, aesthetic, inviting and enchanting. the game must contain visual consistency, by combining the graphic aspects with educational material which both cannot be partial but become one to be synergistic.

The element of asset design in a game is an important component in delivering material in the form of a graphical display displayed on a screen. Therefore, the development of asset design in the game requires special analysis related to the form of adaptation of objects in the real world into virtual displays.

In the educational game @Kar to improve the social aspects, knowledge and care of children developed in the art design department in state university of Malang, there is a need to improve asset design in the game. This increase is needed because the demographic element with the target user, especially the malang city children and Indonesian children, strongly supports the achievement of the goal of making this educational game. Besides that, currently there is still minimal research related to educational games that elevate asset design using local Indonesian design concepts. An asset design concept that has a local Indonesian concept is like what Ahmad Zulfan Naufandi did in the "Ayo Membatik" game that lifts the character with Central Javanese nuances in clothing properties but other asset design elements do not imply a local concept. There is also the game "Pocong Jump" which was developed by Digi Phoenix Studio, in this game the design of Indonesian characters and stories is raised, but the design of other assets does not imply a local concept. This is the basis of the @Kar education game asset development design that selected the asset design concept that has the characteristics of Malang city, both in character design, property design and background design.

The importance of this research is to improve the achievement of character education through educational games, it is necessary to improve visual design that has emotional 
and psychological closeness for users in this case, the city of Malang, the province of Java and Indonesia. It is expected that by increasing asset design in @kar games can improve the quality of character education in elementary school students.

\section{Method}

The type and design of this study uses procedural qualitative research with descriptive references to asset design theory. this study identifies the asset design for the @KAR educational game with the unfortunate city as a visual object. The concept of colors and design styles is appropriate for elementary school children. This visual data fits the theme of the thematic learning of the elementary school curriculum. Thematic patterns are emphasized on activities of knowledge, association and physical activities. Data collection techniques through observation, interviews and survey target audience

This research was conducted with data collection carried out in Malang City and Batu to see the characteristics of character design and coloring concepts that are suitable for elementary school students. Observations were made in several locations in the city of Malang. this location is used as a basis for design visualization on property and background in Malang city.

The development model that was carried out on the educational game design development of @Kar's game can be seen in Figure 1.

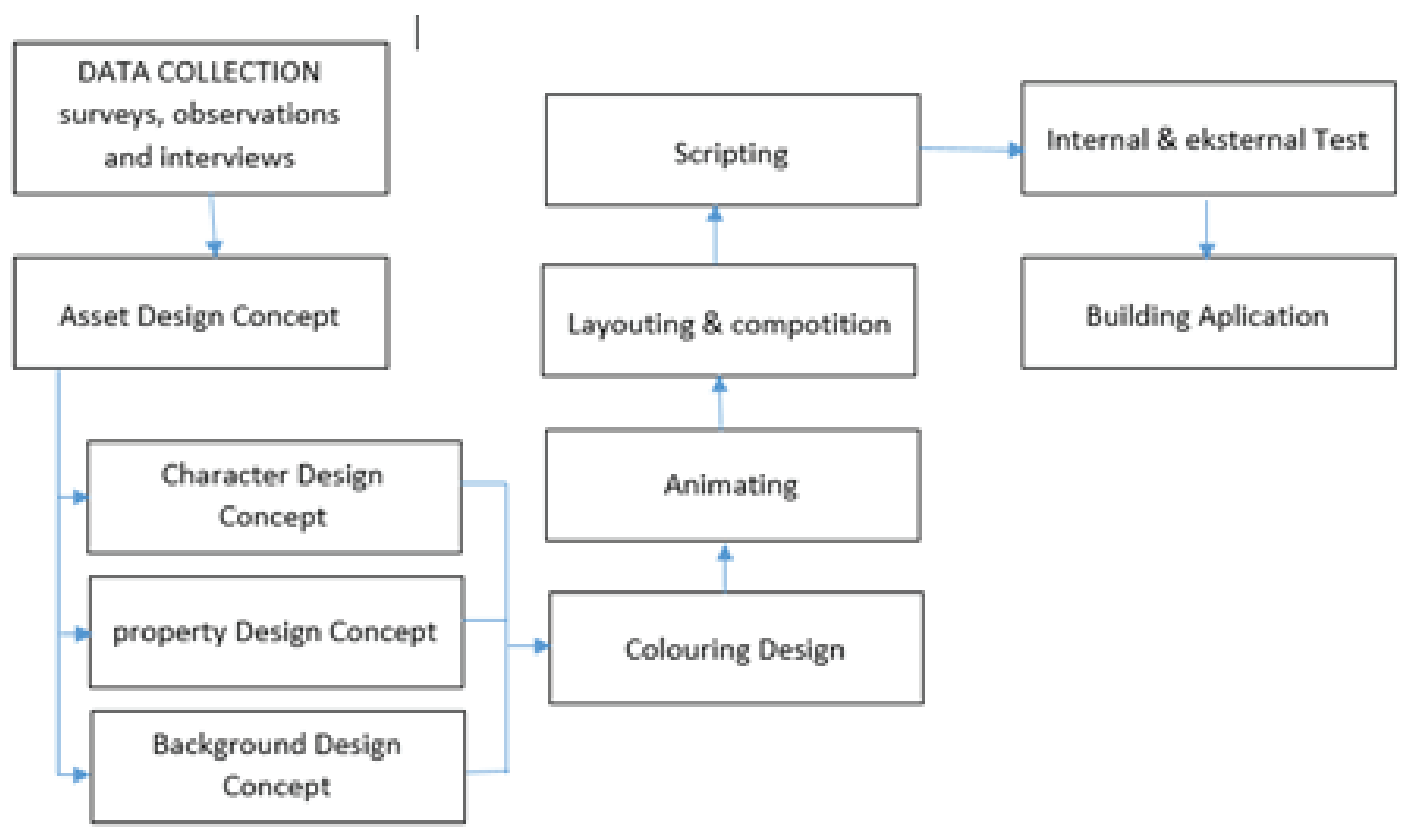

Figure 1: Development Design @Kar Asset Design . 
This research during pre-production consists of data collection and asset design concepts. Data collection consists of surveys, observations and interviews. The asset design concept consists of character design, property design and background design. In the production phase consists of the stages of asset design coloring, the stage of animation design, layouting and scripting. After the production phase is passed, then the trial steps are followed by packaging into an application.

\section{Findings and Discussion}

In this research there are some related findings as the basis of asset design information in this @KAR educational game. Development of Visual Assets in the Game @KAR is a major problem in designing game structures, is combining ideas and desires of players in a visual form. In order for the game to be interesting, it needs to be added an immersion. Immersion is a virtual reality or an impression that brings players into the game world. Immersion is made by adapting the conditions of the real world into a virtual world.

The symbolic analogy approach is a method of identifying an object, then taking the main characteristics of the object. These characteristics must be an element that best represents the object so that the feature can be adapted to another form.

\subsection{Visual design influences the storyline}

The storytelling communication and the anxiety of parents and teachers on the preparation of children read before entering elementary school. About $98 \%$ of parents and all teachers agree that children's activities stare at important images long before the child can read the word. What is interesting is the reason behind their statement, which is $51 \%$ of parents and $54 \%$ of teachers reason that images are important to help children learn to read writing. The results of the questionnaire indicate that parents and teachers more familiar with the function of the picture on the children's reading book reading kindergarten to learn to read than staring at the picture.

\subsection{Basic concepts of visual assets educational game character @KAR}

In developing the visual concept of asset, educational games are based on the pattern of developing thematic-based character education. In the development of character education, it is emphasized on the elements of knowledge, social and motoric. Based 
on the elements of the review, a deeper description is made, namely 1 ) the element of knowledge will be chosen visual design of school atmosphere, where the school visual concept is chosen based on the school concept as a place to acquire knowledge and knowledge. home., 3) motoric elements selected visual design atmosphere of the place to hang out, implying activities.

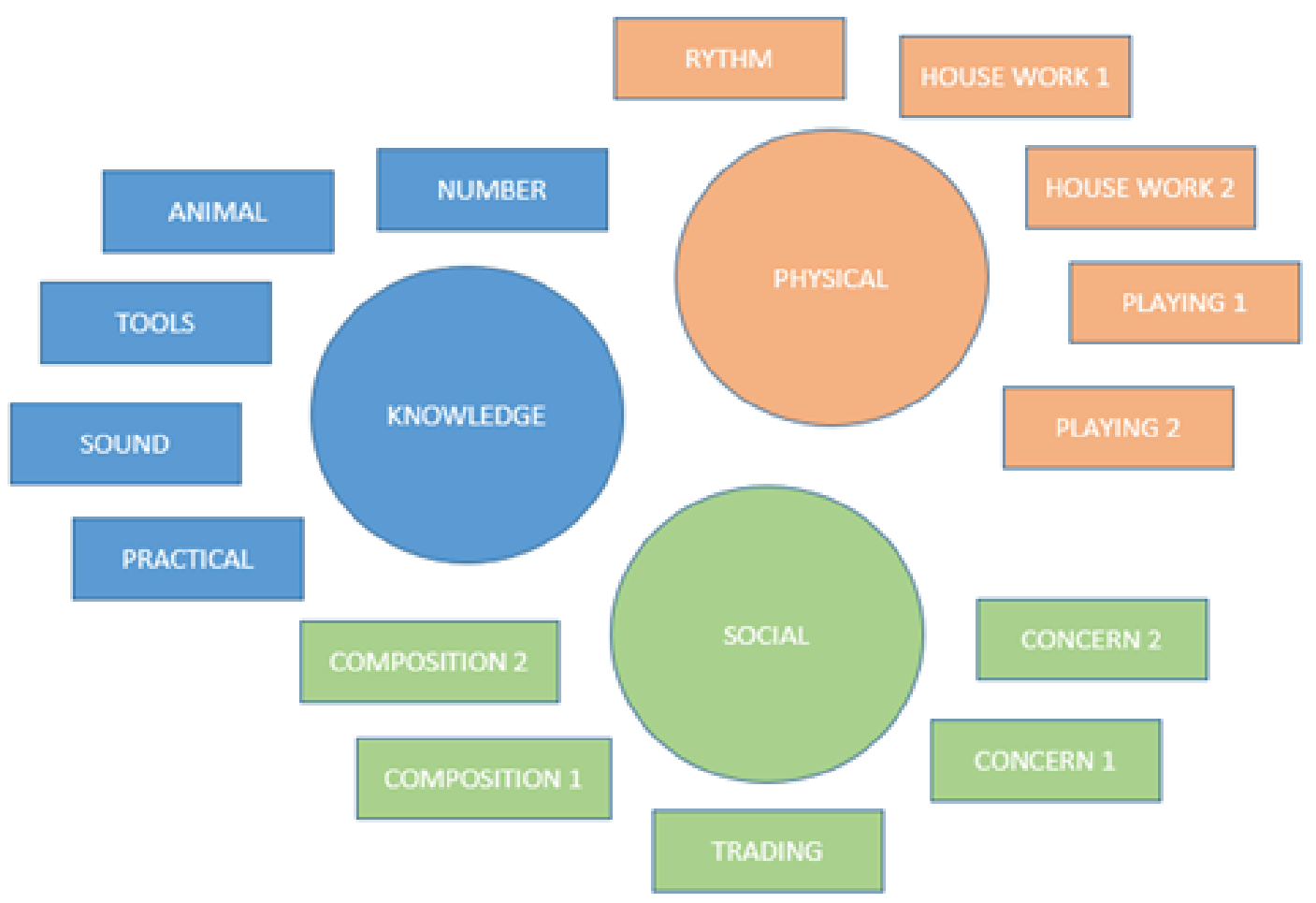

Figure 2: The description of the educational game thematic concept.

Based on data collection obtained several findings related to the basic components that will become the basis of educational game design. Data collection involves children and parents of elementary school students as respondents. These basic components include the type of color, the coloring style, the type of game font and the style of the dialog box. The results of the analysis can be seen in Figure 3 .
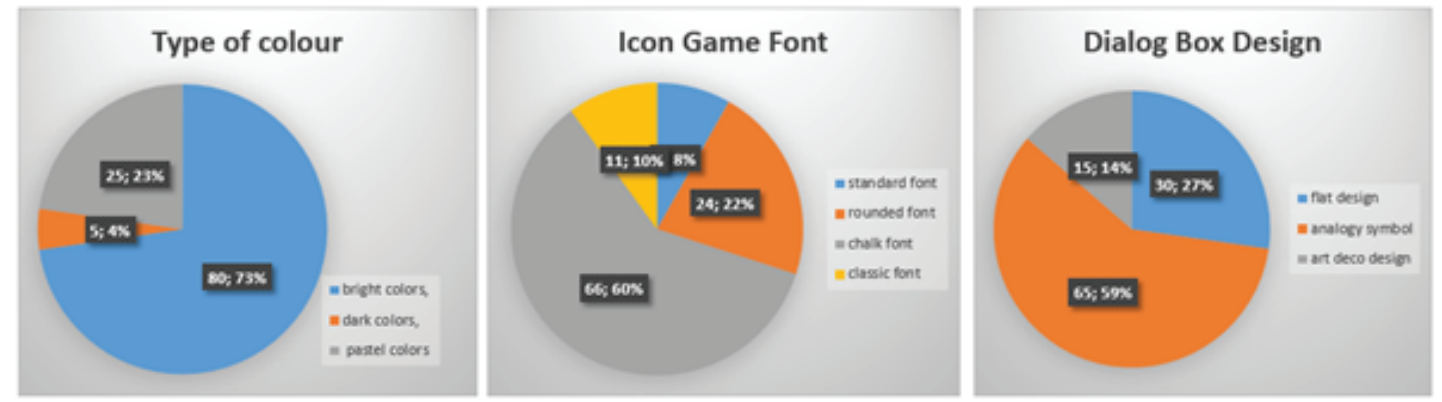

Figure 3: Analysis of the results of data collection. 


\subsection{Visual asset design components character education games @KAR}

Based on the basic concepts above can be derived in several design components, including characters, backgrounds and properties in the @KAR educational game.

\subsubsection{Character design}

In this @KAR educational game, there are 2 character designs, namely the main design, namely the character of boys and girls. While the design of supporting characters is the character of the teacher and the NPC. Character design references are based on the concept of 1) elementary school children both boys and girls wearing school uniforms and wearing daily clothes; 2) the concept of the teacher's mother here uses the concept of the teacher's mother to wear the national teacher's uniform. Figure 2 shown the refference image, sketch and the result design of the character design.

\subsubsection{Background design}

In this @KAR educational game there are 3 background designs, where this background design is based on an element of review on this @KAR educational game. Background design concepts: 1) Background Design: Knowledge; 2) Background Design: social; 3) Background Design: the physical

\subsubsection{Property design}

This property design refers to the thematic concept of the game contained in each element of learning. This type of property includes flowers, animals, household appliances, stationery, laboratory equipment, play equipment, books and vehicles Figure 6 and 7 was example for property design.

\section{Conclusions and Suggestions}

Based on the results of research on the application of asset design improvements in the educational game @KAR. It was concluded that the result of the visual asset design change from the @kar educational game used the local design concept of the malang city. The concept is based on the criteria for the pattern of activities carried out. Activities 

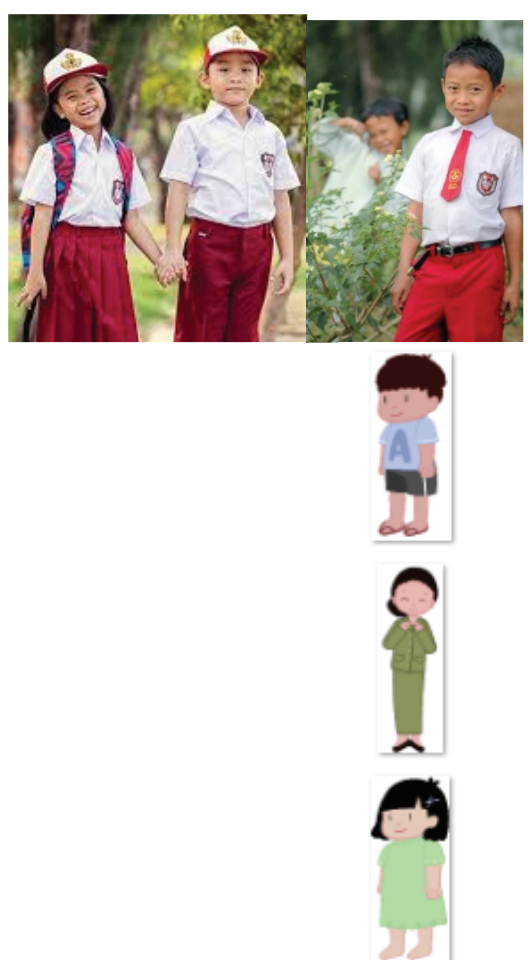
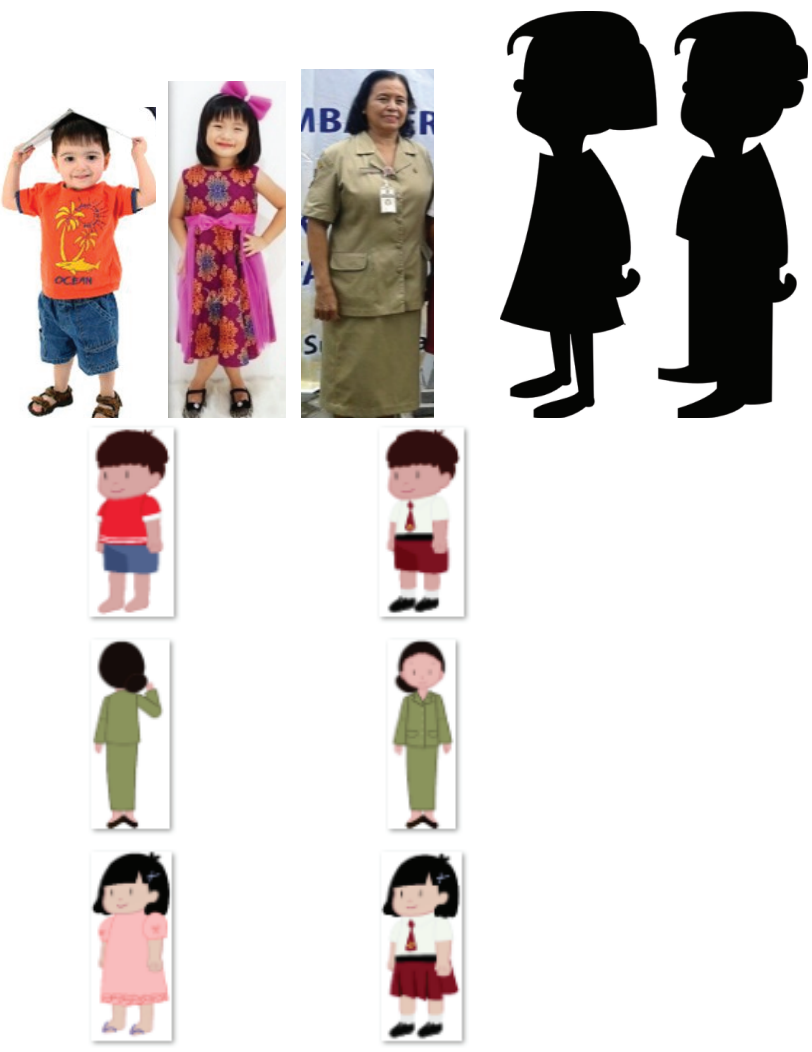

Figure 4: Refference of karacter design, sketch concept and caracter design.
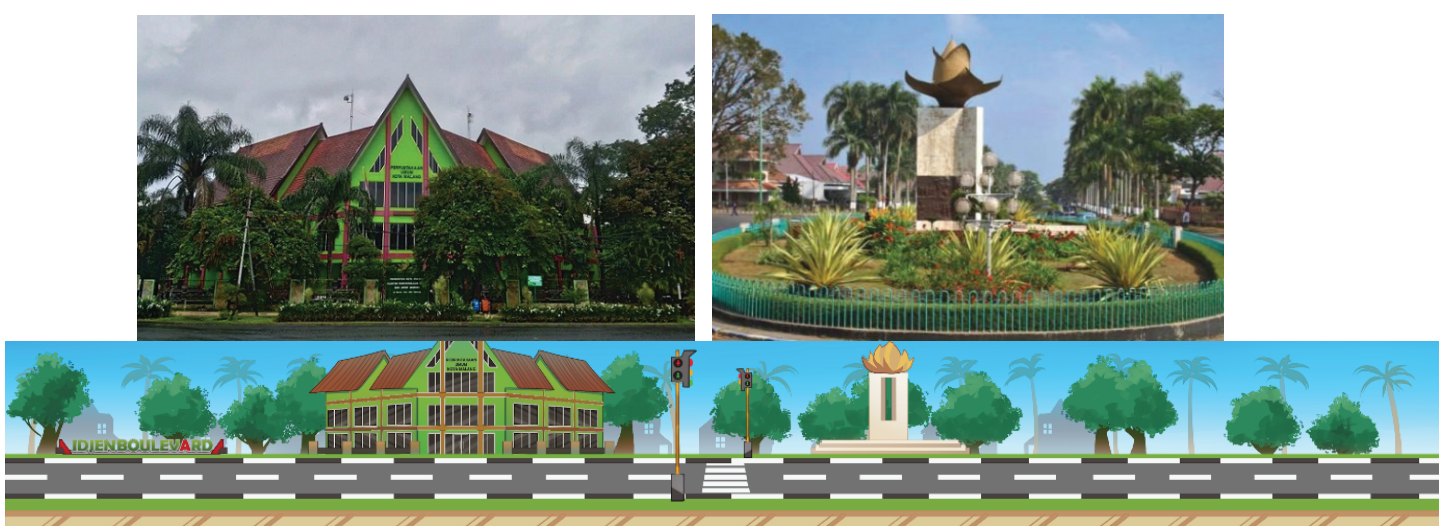

Figure 5: Social design background concept 1, refference and final concept.

include knowledge activities, social activities and physical activities. The concept of visual asset design is divided in 1) Character design; 4 designs were produced including the characters of boys, girls, mother teachers and NPCs; 2) Background design; 3 types of background location with total background of 8 backgrounds; and 3) Property design; a total of 30 properties consist of 8 animated properties and 22 static image properties. The advice given in this game is to develop the design of visual assets using other city design concepts in Indonesia. 


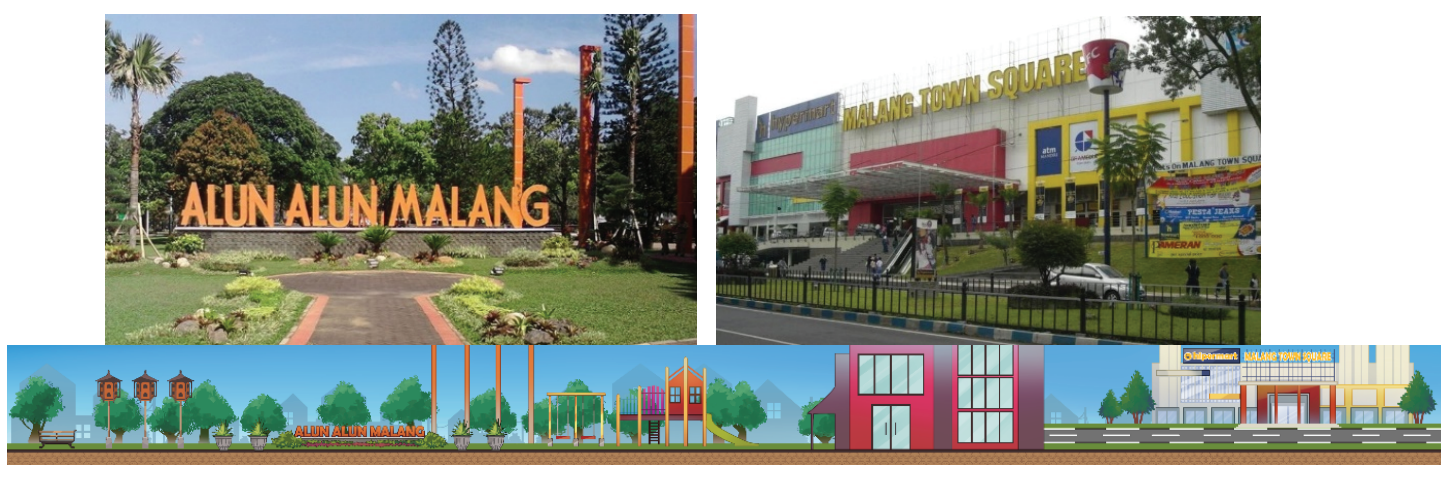

Figure 6: Social design background concept 2, refference and final concept.
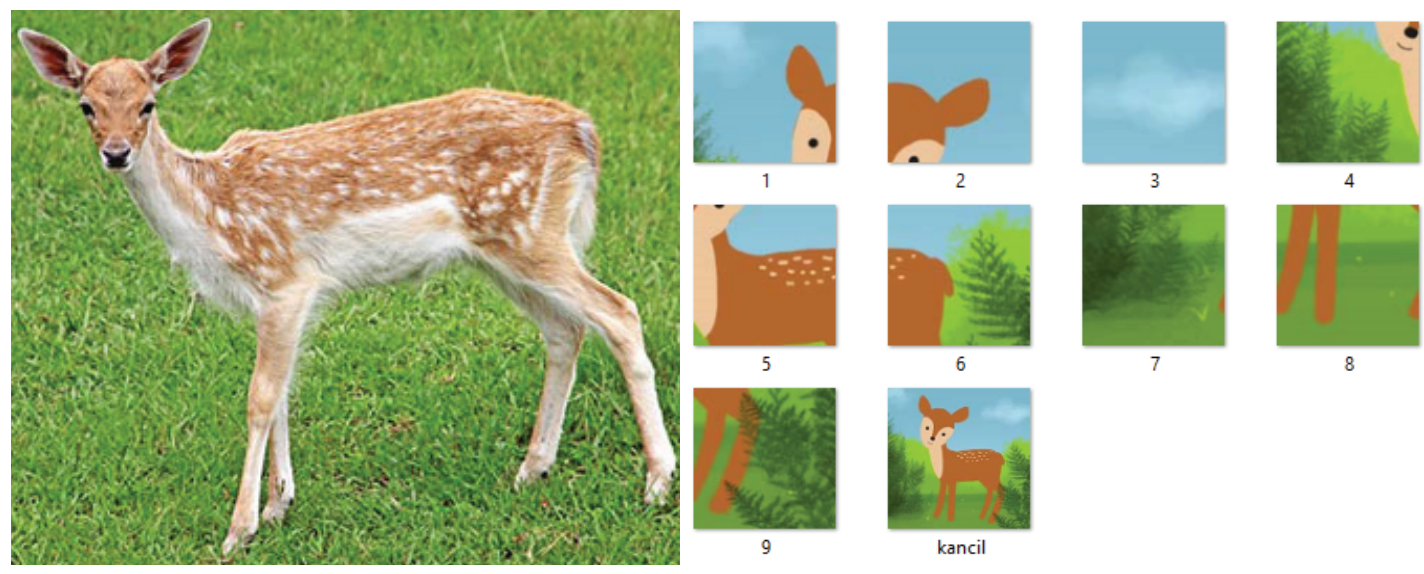

4
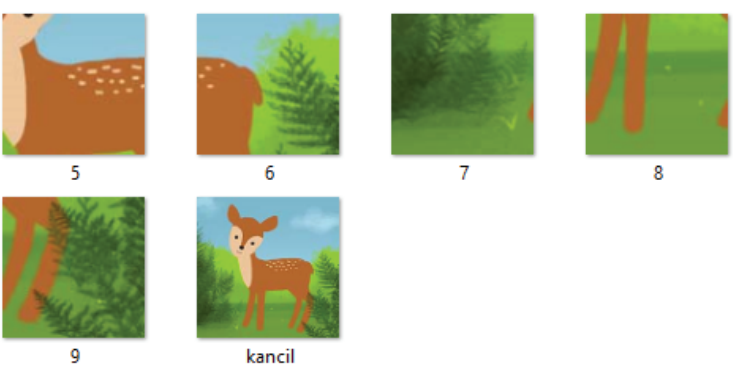

Figure 7: Property design: animal for puzzle game.
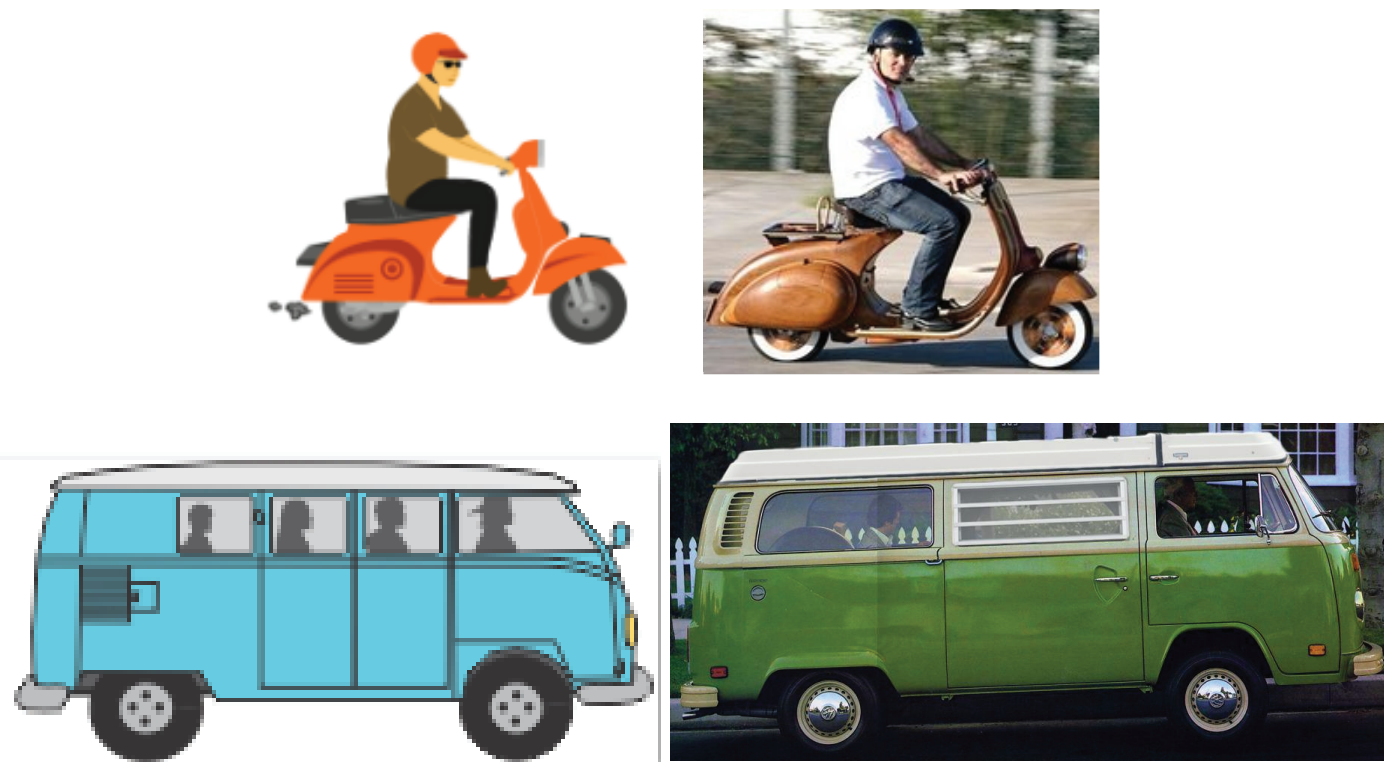

Figure 8: Property design: car. 


\section{References}

[1] Kress, Gunther dan van Leeuwen, Theo. 2006. Reading Images: The Grammar of Visual Design. London: Routledge.

[2] E. Bethke, Game Development and Production (Wordware Publishing, Inc., Plano, Texas, 2003).

[3] S. Rabin, Introduction to Game Development (Charles River Media, Boston, 2005).

[4] H. Chandler, The Game Production Handbook (Charles River Media, Boston, 2006).

[5] I. van de Weerd, S. Brinkkemper, J. Souer, and J. Versendaal, A Situational Implementation Method for Web-based Content Management System-applications,

[6] Software Process: Improvement and Practice 11(5), 521-538 (2006).

[7] Cooper, Alan. About Face 3. The Essentials of Interaction Design, ISBN 9780470084113, www.newsrider.com, USA, 2008

[8] Hoekman, Robert, Designing the Moment: Web Interface Design Concepts in Action,www.newsrider.com, USA, 2008

[9] Reilly, Designing Interface second edition, ISBN 978-1-449-37390-4, Canada, 2010Padia Keval, 2015, http://www.devsaran.com/blog/flat-ui-design-keyprinciples-and-possibiliti

[10] CHOW, A. F., KELLY, C. W. \& MAES, J. (2011) Deal or No Deal: using games to improve student learning, retention and decision-making. Internatlional Journal of Mathematical Education in Science and Technology, 42, 259-264.

[11] FUSZARD, B. (2001) Gaming. IN LOWENSTEIN, A. J., BRADSHAW, M. J. \& FUSZARD, B. (Eds.) Fuszard's innovative teaching strategies in nursing. 3rd ed. Gaithersburg, MD, Aspen Publishers 